\title{
The 1991-2004 Evolution in Life Expectancy by Educational Level in Belgium Based on Linked Census and Population Register Data
}

\section{L'évolution de l'espérance de vie par niveau d'instruction en Belgique de 1991 à 2004 sur la base de données de recensement liées au registre de la population}

\author{
Patrick Deboosere · Sylvie Gadeyne • \\ Herman Van Oyen
}

Received: 19 July 2007/ Accepted: 18 April 2008/Published online: 19 June 2008 (C) Springer Science+Business Media B.V. 2008

\begin{abstract}
The aim of this study is to determine trends in life expectancy by educational level in Belgium and to present elements of interpretation for the observed evolution. The analysis is based on census data providing information on educational level linked to register data on mortality for the periods 1991-1994 and 2001-2004. Using exhaustive individual linked data allows to avoid selection bias and numerator-denominator bias. The trends reveal a general increase in life expectancy together with a widening social gap. Summary indices of inequality based on life expectancies show, however, a more complex pattern and point to the importance to include the shifts in population composition by educational level in an overall assessment of the evolution of inequality by educational level.
\end{abstract}

Keywords Life expectancy - Social inequality - Socioeconomic position · Educational level $\cdot$ Mortality $\cdot$ Belgium

Résumé L'objectif de l'étude est de déterminer le sens et l'ampleur de l'évolution des inégalités en espérance de vie en Belgique selon le niveau d'instruction. L'analyse part des données des recensements qui fournissent l'information sur le niveau d'instruction. Ces données ont été liées au registre de la population qui fournit l'information sur la mortalité pour les périodes 1991-1994 et 2001-2004. L'utilisation de données exhaustives et d'un enregistrement de la mortalité lié

P. Deboosere $(\bowtie) \cdot S$. Gadeyne Interface Demography, Vrije Universiteit Brussel, Pleinlaan, 2, 1050 Brussel, Belgium e-mail: Patrick.Deboosere@vub.ac.be

H. Van Oyen

Scientific Institute for Public Health, Brussels, Belgium 
directement aux données du recensement évite des erreurs de sélection et du biais entre numérateur et dénominateur. On peut constater qu'en général l'espérance de vie progresse pour tous les niveaux d'éducation mais que cela va de pair avec un élargissement des inégalités. L'utilisation d'indices d'inégalité montre néanmoins une réalité plus complexe et la nécessité d'inclure l'évolution de la composition de la population par niveau d'éducation dans une évaluation globale de l'évolution des inégalités.

Mots-clés Espérance de vie · Inégalité sociale · Position socio-économique · Niveau d'instruction · Mortalité · Belgique

\section{Introduction}

After the Second World War, the development of welfare states led to the belief that inequalities in health would gradually disappear. And yet, the Black Report and the Whitehall studies pointed out significant health inequalities in highly developed countries (Marmot 1995; MacIntyre 1997), generating a growing body of research by a multi-disciplinary community. Over the past decades, strong evidence has been accumulated across a large set of industrialised countries that inequalities in health have persisted, with differences in healthy life expectancy among the extremes of the social ladder ranging from a couple of years to over a decade (Pappas et al. 1993; Valkonen 1999; Mackenbach 2005). Several studies observed a widening of health and mortality inequalities by socioeconomic status over the past decades (Fox 1989; Harding 1995; Valkonen 1999; Martikainen et al. 2001a; Mackenbach 2005).

Socioeconomic position refers to the structural location, reflecting the social and economic characteristics that determine the position individuals and groups hold within society (Kunst 1997; Gadeyne 2006). In order to capture the impact of socioeconomic characteristics in industrialised countries, it is generally agreed that at least three dimensions must be considered as determinants for the socioeconomic environment both for individuals and for society: income, education and work (Kunst and Mackenbach 1994a). Some authors add wealth as a fourth dimension, because it is much more unevenly distributed than income (Hummer et al. 1998) and also it adds the intergenerational transfers of material resources. The measurement of all these indicators is far from straightforward. Much energy has been devoted to their harmonisation and standardisation for international comparison (Valkonen 1993; Mackenbach et al. 1997; Kunst et al. 1998). Among those indicators, education has a number of advantages. First, it applies to the adult population regardless of labour market position. Second, it affects potential earnings and access to material resources that influence health, and therefore shares some of the health effects with other indicators (occupation, income and wealth) and is strongly correlated with them (Galobardes et al. 2004). Third, as formal education is normally completed in young adulthood and partly reflects the characteristics of the family and community of origin, it is an indicator that measures early life socioeconomic position and that remains relatively stable over the life course from early adulthood onwards (Davey-Smith et al. 1998). 
It is worth noting that the meaning of educational level as an indicator of socioeconomic position varies for different birth cohorts because of the upward secular trend in educational attainment. While finishing secondary education before the Second World War resulted in a relatively high social position, this is no longer the case nowadays. This is an important problem if we wish to compare socioeconomic positions across birth cohorts. Using a relative index of inequality has been one of the most common solutions for correcting for the overrepresentation of lower educated persons among the oldest birth cohorts (Kunst and Mackenbach 1995; Kunst 1997). Besides of being an indicator of socioeconomic position, education is also related to cognitive abilities and informational resources, helping individuals to mobilise health resources (Elo and Preston 1996). Clearly, the emancipating role of education plays a crucial role and also affects health indirectly by providing skills in mastering and finding solutions for complex day-to-day problems and by endowing people with a sense of control over their life (Mirowsky and Ross 2007).

Formal education is a good indicator to measure educational capital both at the individual level and the societal level. Analysing inequalities in health from this point of view has a double entry: it concerns both inequality and progress. If persons with different educational attainments perform differently within the same societal context, then higher educated populations could be regarded as a kind of vanguard group in the health transition. Just as analysing data of Japanese men and women helps to understand future developments of longevity and factors that contribute to healthy life expectancy, we can turn to the higher educated to better understand and capture future health processes. Historically, the improvement in the educational level of a population reflects the progress to reduce risks with a negative impact on health (Hayward et al. 2006). Our interest thus focuses on the absolute progress in educational attainment.

In Belgium, there is a long tradition of research in health and mortality inequalities, and many papers explicitly dealing with the subject have been published over the past decades (Lagasse and Namurois 1982; Vuylsteek 1984; Schepers et al. 1985; Lagasse et al. 1990, 1992; Masuy-Stroobant 1992; Raes et al. 1993). Recently, Belgian research has been boosted by the availability of the health interview surveys conducted in 1997 (Van Oyen et al. 2002, 2005) and of the national mortality database, i.e. a linkage of census data and register data on mortality (Gadeyne and Deboosere 2002; Bossuyt et al. 2004).

The aim of this article is to investigate trends in life expectancy by educational level in Belgium at the turn of the millennium. In order to calculate life expectancies, we used the 1991 and 2001 census data linked to mortality and migration data from the National Register. The character of the data-exhaustive individual census records, individually linked to mortality data during a follow-up period of 3 years-enables a very precise evaluation of education-specific mortality trends. First, we investigate if and how life expectancy by educational level has changed over the period 1991-2004. Second, we analyse to what extent these changes can be interpreted as changes in health inequalities. 


\section{Data}

Mortality data generally come from vital statistics registration systems, which have to be related to census data or other appropriate population data in order to compute the mortality rates. This combination of data from two different sources can generate a large number of errors due to inappropriate matching of the two sources (Kunst and Mackenbach 1995). In this study, based on a linkage of the 1991 and the 2001 censuses to register data on mortality and emigration in 1991-1994 and 20012004 , record linkage was based on a unique identifier present in both the census and register files. As a consequence, socio-demographic characteristics in the census were unambiguously matched to migration and mortality data in the population register in a follow-up period of three years after each census.

The mortality data can be considered as almost fully accurate. Problems of death registration account for $<0.05 \%$ of the annual deaths and mainly relate to late registration of deaths occurring outside the country. The registration of emigration is more problematic, as persons leaving the country often omit to report their emigration to the authorities, sometimes resulting in a considerable time lag in the registration of emigration. Nevertheless, the internal consistency of the migration data suggests a high degree of accuracy for the period 1991-1994. In 2001, the emigration data may be slightly less accurate, as evidenced by the fact that emigration is three times higher in the first year of observation than in the two consecutive years. The explanation is likely to be the accumulation of inaccuracies in the population registers of some municipalities during the intercensal period. Corrections of the register based on non-returned census forms resulted in a sudden surge in emigration registration in the first year after the census. The importance of emigration is, however, relatively small and errors due to possible overestimation of the denominator will not necessarily alter our research results. Moreover, it mostly concerns non-returned census forms and these cases are excluded from the analysis.

Education is measured as a categorical variable by attained level of education. The categories are comparable with the international ISCED classification. The attained level of education is preferred above the number of years of schooling or the age at the end of the studies, as these do not discriminate very well between slower completion of the educational curriculum and higher levels of attainment.

Substantial efforts were made to clean and control the educational data in order to guarantee comparability between the two census files. Analysis of the census data shows clear differences in the response pattern between 1991 and 2001 due to the question wording. The differences are marginal as far as secondary and tertiary education are concerned.

The main problem with the 1991 data arises from the fact that persons without formal education cannot be distinguished from non-response. Respondents were asked to tick the highest diploma they had obtained without the possibility of choosing an option "without formal diploma". This resulted in a high non-response, mainly among older respondents who finished primary school and sometimes lower secondary school-as can be deduced from the number of years of school attendance-without receiving a formal certificate. In the 2001 census, the question wording was modified, resulting in a much higher response rate. 
Selectivity in non-response can influence the outcome. Analysis of the missing data shows that non-response is selective in at least two regards. Lower educated persons are in general less inclined to declare their level of educational attainment, this phenomenon being accentuated in the 1991 census due to the question wording. Non-response is also related to health and the risk of dying. It is evident that in the stressful situation of a terminal illness, people or their family are not preoccupied with filling in the census form. In addition, ill persons are not necessarily at home and may be hospitalised or transferred to long-term care facilities. In other words, older and sick persons with a high risk of dying have a higher risk of not answering the census. Analysis of the data shows a large overrepresentation of non-response for education among persons who die in the months following the census.

The dataset delivered by Statistics Belgium allows us to control the group composed of persons with no formal education or with non-response for education in $1991(27 \%)$ using the answers on education in the 2001 census. Based on these 2001 data, among the non-response in 1991, less than 5\% could be classified in the academic or non-academic higher educational level. About $40 \%$ of the non-response in 1991 is composed of persons with a primary education in 2001 and about $25 \%$ with a lower secondary education. Finally, $10 \%$ of the non-response in 1991 pertains to persons who confirmed having no formal education in 2001 and $15 \%$ of those who did not answer the question on educational attainment in 1991 did the same in 2001.

Due to mortality or emigration, 1.37 million persons registered in the 1991 census were no longer present in the census of 2001. For most of them the educational level in 1991 was known. For the non-response among those who had disappeared, we applied a weighting factor with a similar distribution to the pattern we found in the analysis of surviving non-respondents. As mortality differs by educational level, we also applied a correction factor for differential mortality. The result is summarised in Tables 1, 2 and gives a comparable and more correct distribution of educational attainment of men and women above age 25 in 1991 and 2001. However, the calculation of life expectancies proper is restricted to the original data and the reason for this restriction will be further documented in the discussion section.

Table 1 Census populations and register-based mortality in 1991-1994 and 2001-2004 by sex

\begin{tabular}{|c|c|c|c|c|}
\hline & \multirow{2}{*}{ Population aged $25+$} & \multicolumn{3}{|c|}{ Deaths in follow-up period } \\
\hline & & Year 1 & Year 2 & Year 3 \\
\hline \multicolumn{5}{|c|}{ (March 1991) } \\
\hline Men & $3,248,365$ & 51,349 & 50,830 & 52,116 \\
\hline Women & $3,547,930$ & 51,042 & 50,084 & 52,129 \\
\hline \multicolumn{4}{|c|}{ (October 2001) } & 104,245 \\
\hline Men & $3,481,352$ & 50,818 & 50,980 & 50,096 \\
\hline Women & $3,766,701$ & 52,327 & 53,019 & 51,375 \\
\hline Total & $7,248,053$ & 103,145 & 103,999 & 101,471 \\
\hline
\end{tabular}


Table 2 Absolute and percent distribution by educational level of the total Belgian population aged 25+ in 1991 and 2001

\begin{tabular}{lrrrr}
\hline & Men (1991) & Men (2001) & Women (1991) & Women (2001) \\
\hline Absolute numbers & & & & \\
No answer & 158,781 & 211,579 & 205,232 & 262,991 \\
No formal education & 109,407 & 136,963 & 145,192 & 170,634 \\
Primary education & 883,074 & 522,139 & $1,141,239$ & 703,914 \\
Lower secondary & 752,107 & 799,541 & 791,609 & 843,202 \\
Higher secondary & 771,766 & 842,516 & 730,363 & 816,344 \\
Tertiary education & 573,230 & 856,182 & 534,296 & 871,049 \\
Total population & $3,248,365$ & $3,368,920$ & $3,547,930$ & $3,668,134$ \\
Percentages & & & & 7 \\
No answer & 5 & 6 & 6 & 5 \\
No formal education & 3 & 4 & 4 & 19 \\
Primary education & 27 & 16 & 32 & 23 \\
Lower Secondary & 23 & 24 & 22 & 22 \\
Higher secondary & 24 & 25 & 21 & 24 \\
Tertiary education & 18 & 25 & 15 & 5 \\
\hline
\end{tabular}

For each three-year period we consider a semi-closed population as we are studying population attrition by death or emigration and do not allow for immigration. In order to keep the 1991 and the 2001 populations as comparable as possible, we restricted the 2001 population to persons already living in Belgium in 1991. Migration can be considered as a perturbing factor if we want to study trends in life expectancy by educational level. Immigration indeed substantially influences the population composition by educational level and several studies have illustrated the existence of a healthy migrant effect (Abraído-Lanza et al. 1999; Razum et al. 2000; Razum and Rohrmann 2002). As a large proportion of recently arrived immigrants have no formal education or only primary education, including them could considerably alter the position of the lowest educated and make it difficult to clearly interpret the results.

\section{Methods}

In order to measure mortality differences, life expectancy is preferred to the frequently used odds ratios, relative risks or standardised mortality rates/ratios. The simplicity of these indicators is an important advantage, but they tend to reflect the intensity of mortality and do not report on the prematurity of death (Shkolnikov et al. 2001). Life expectancy, in contrast, measures the essential time dimension of mortality, has the advantage of ready interpretation and is, in addition, easy to use across populations.

Life expectancy is better suited to capture the double conceptual approach of the relationship between educational attainment and mortality. In recent decades, 
research on the education-mortality relationship has often been dominated by the inequality aspect and relative risks of mortality are well adapted to this research. Life expectancy by educational level offers scope for a more global assessment including both the health inequalities aspect and the role of education in the improvement of life expectancy.

The two datasets with linked population-at-risk and mortality data allow for analysing trends in education-specific life expectancy without the classic numeratordenominator problem. In order to enhance stability and reliability, life expectancy is calculated for the three-year period following each census. The use of a three-year period also neutralises the possible bias of selective missing data, the mortality risk of non-respondents being high in the first months after the census due to serious health problems. The census of 1991 was held on 1 March; the census of 2001 on 1 October. For all persons present in each census, mortality and migration data were drawn from the population register over a follow-up period of three years. Based on this information, the exact number of person-years lived is calculated by age, sex and educational level. Age-specific death rates $\left({ }_{n} M_{x}\right)$ were calculated and converted into age-specific probabilities of dying ${ }_{n} q_{x}$ by applying the simplified equation (Shryock et al. 1971; Newell 1988). The life tables were computed using the classic life table formulas based on one-year intervals.

In order to evaluate changes in inter-group inequalities, we introduced summary indices of inequality based on life expectancies. In the case of education, where policy plays an important role in the population distribution, the evaluation of the widening or narrowing of the life expectancy gap between educational groups should also address changes in the educational distribution in the population.

Several measures have been developed to take account of changes in population distribution by socioeconomic category. Such indices have been constructed for mortality rates (Kunst and Mackenbach 1994a, b), but can also be determined for life expectancies. Shkolnikov and colleagues have demonstrated that the population attributable risk (PAR) index can be transformed into a population attributable life loss (PALL) index. In absolute terms, this index represents the increase in overall life expectancy that would be achieved if all groups had the life expectancy of the best group. In relative terms, it is equal to the percentage increase in overall life expectancy that would occur if all groups had the life expectancy of the best group (Shkolnikov et al. 2001).

$$
\begin{gathered}
\text { PALL }_{\mathrm{abs}}=e_{x}^{\text {highest }}-e_{x} \\
\text { PALL }_{\mathrm{rel}}=\sum_{i}\left(\left(e_{x}^{\text {highest }}-e_{x}^{i}\right) * p_{x}^{i} / e_{x}\right)
\end{gathered}
$$

If the proportions of the subgroups were constant over all the age groups, then we would have the following equation: $\mathrm{PALL}_{\mathrm{abs}}=\mathrm{PALL}_{\mathrm{rel}} * e_{x}$ (Shkolnikov et al. 2001).

This equation does not hold when the proportions of the subgroups are changing over time (in a cohort life table) or by age (in a period life table). The PALL abs $_{\text {may }}$ differ considerably depending on whether it is deduced directly from the life expectancies or whether it is deduced from the PALL $L_{\text {rel }}$, especially in the case of a period life table where proportions of the subgroups by age are completely 
independent from the older ages. A legislative change in the age of compulsory education will, for instance, produce important and abrupt shifts in the educational composition by age. This is not a problem for the PALL ${ }_{a b s}$, based on the absolute difference between life expectancies, as $e_{x}^{\text {highest }}$ and $e_{x}$ both take into account the mortality rates and the educational composition of all ages above age $x$. The PALL $_{\text {rel }}$, in contrast, is very sensitive to age-specific changes in the educational composition. In order to capture the impact of the composition effect, it is appropriate to consider the population-weighted life expectancy loss as a composite measure of inequality and to distinguish on the one hand the PALL-index in absolute terms and on the other hand the Composite Index of Inequality (CII). The $\mathrm{CII}$ is simply equal to the sum of the population-weighted life expectancy losses: $\mathrm{CII}_{\mathrm{abs}}=\sum_{\mathrm{i}}\left(e_{x}^{\text {highest }}-e_{x}^{i}\right) * p_{x}^{i}$. In relative terms, the $\mathrm{CII}_{\mathrm{rel}}$ is identical to the PALL $_{\text {rel }}$ proposed by Shkolnikov and colleagues.

The CII quantifies the combined effect of inequality in LE and the population distribution of educational attainment. The CII is not a decomposition in order to assess the respective contribution of population structure and LE by educational attainment to total LE, neither is it equal to PALL $\mathrm{abs}_{\text {as }}$ anly the population fractions of the concerned birth cohort at age $x$ are taken into account and combined with the LE based on the observed mortality rates of all birth cohorts above age $x$.

\section{Results}

Table 3 summarises the results. Life expectancies by gender and observation year follow the well-known gradient by educational attainment.

During the observation period, life expectancy increased in all educational groups except among women without formal education. The increase varies

Table 3 Life expectancy and summary indices of inequality at age 25 by educational level and sex, 1991 and 2001

\begin{tabular}{lcccccr}
\hline & $\begin{array}{l}\text { Men } \\
(1991)\end{array}$ & $\begin{array}{l}\text { Men } \\
(2001)\end{array}$ & $\begin{array}{l}\text { Change } \\
(91-01)\end{array}$ & $\begin{array}{l}\text { Women } \\
(1991)\end{array}$ & $\begin{array}{l}\text { Women } \\
(2001)\end{array}$ & $\begin{array}{r}\text { Change } \\
(91-01)\end{array}$ \\
\hline $\begin{array}{l}\text { No diploma } \\
\begin{array}{l}\text { Primary } \\
\text { education }\end{array}\end{array}$ & 47.45 & 47.56 & 0.11 & 54.47 & 53.98 & -0.49 \\
$\begin{array}{l}\text { Lower } \\
\quad \text { secondary }\end{array}$ & 47.84 & 49.29 & 1.45 & 55.09 & 56.17 & 1.08 \\
$\begin{array}{l}\text { Higher } \\
\quad \text { secondary }\end{array}$ & 50.66 & 51.33 & 1.67 & 56.65 & 58.00 & 1.35 \\
$\quad \begin{array}{l}\text { Tertiary } \\
\quad \text { education }\end{array}$ & 52.68 & 55.03 & 2.35 & 57.69 & 59.90 & 2.21 \\
$\begin{array}{l}\text { Total LE } \\
\text { PALLabs }\end{array}$ & 49.15 & 51.38 & 2.23 & 55.42 & 57.09 & 1.67 \\
$\quad$ CIIabs & 3.53 & 3.65 & 0.12 & 2.28 & 2.81 & 0.53 \\
CIIrel (\%) & 2.19 & 1.92 & -0.27 & 0.82 & 0.82 & 0.00 \\
\hline & 4.47 & 3.73 & -0.74 & 1.48 & 1.43 & -0.05 \\
\hline
\end{tabular}


considerably according to educational level. The smallest increase and even a decrease is observed in the groups without formal education, the largest increase is in the groups with tertiary education (2.35 years in men and 2.21 in women). The increase in life expectancy between 1991 and 2001 by educational level follows the existing gradient, resulting in widening differences by educational level. Higher education not only means higher life expectancy, but also implies a faster increase in life expectancy compared to lower educational levels. The result is an overall increase in disparity in life expectancy between the highest and the lowest educated, attaining in 20017.47 years for men (compared to 5.23 in 1991), and 5.92 years for women (compared to 3.22 in 1991).

The gender gap in life expectancy is closing and mortality has declined faster among men than among women within each educational level. In 2001, life expectancy of the highest educated men attained life expectancy of the lowest educated women. Among women, disparities have grown faster than among men and the gap between highest and lowest life expectancies in women increased more both in relative and absolute terms than in men.

As can be observed in Table 3, life expectancy increased almost as fast for the overall male population as for the highest educated men. This results from the combined effect of an increase in life expectancy among the highest educated men on the one hand and an increase in the proportions of higher educated on the other. There has been a phenomenal shift in the overall educational distribution as documented in Table 2. The fraction of the male population with tertiary education has risen from $17.6 \%$ to $25.4 \%$ and the fraction with primary or without formal education has decreased from $27.2 \%$ to $15.5 \%$. The indicators of total impact in Table 3 clearly show this trend for men. The population attributable life loss due to inequalities in life expectancy barely changes between 1991 and 2001. The composite index of inequality is even decreasing both in absolute ( 0.3 years $)$ and relative terms. The widening disparity in life expectancy by educational level among men is thus compensated by the important shift towards higher educational attainment.

The shift in educational attainment among women is even more spectacular than men. In the overall population, the proportion of women with tertiary education has increased from $15.1 \%$ to $23.8 \%$ and the proportion with primary education at most has dwindled from $32.2 \%$ to $19.2 \%$ (Table 2). This shift is, however, barely compensating for the huge increase in disparity in life expectancy among women with the PALL increasing in absolute terms by half a year. The rapid increase in educational attainment in the younger age groups results, however, in a neutralisation of the growing inequality in mortality between the educational levels, as expressed in the composite indices of inequality.

Figure 1 presents the indicators of population attributable life loss for the age range 25-90. Between 1991 and 2001, men show a slightly worsening PALL in absolute terms up to the age of 75. For women, the trend in PALL at age 25 is reproduced for all ages. While the PALL for women is lower than for men in 1991 and comparable from age 72 onwards, it overtakes the PALL for men at age 68 in 2001 and remains higher up to the oldest ages.

The trend in CII by age (Fig. 2) is much more volatile, as it is directly influenced by changes in the educational population distribution by age. The widening 


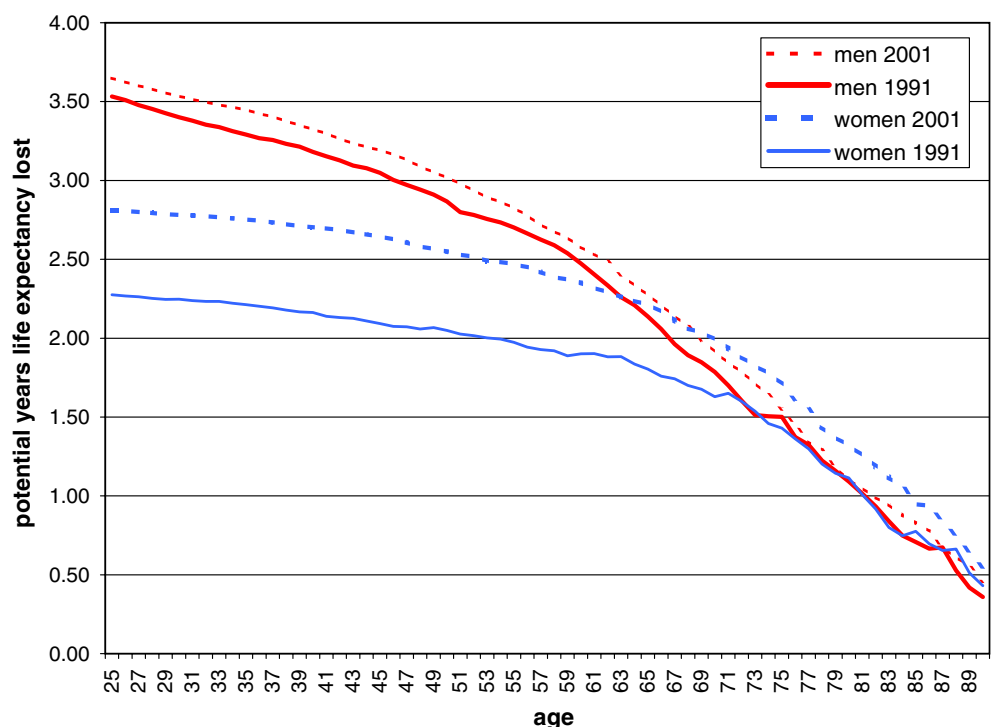

Fig. 1 "Population Attributable Life Loss*" in absolute terms for men and women by age in 1991 and 2001. * (PALLabs $=e_{x}^{\text {highesteducationallevel }}-e_{x}$ ), the difference between life expectancy at age $x$ in the highest educational level and life expectancy at age $x$ in the total population

inequalities among women are largely compensated by the growing numbers of higher educated women until age 37 in absolute terms and until age 55 in relative terms. For the older age groups, inequality is increasing as indicated by the CII. Among men, inequality in terms of the CII is in general decreasing, but the improvement does not hold for all ages and there is even an increase in inequality in the age group 65-75.

Table 4 gives an overview of the increase in life expectancy between 1991 and 2001 by educational level at selected ages. The table indicates that a substantial share of the increase in life expectancy can be attributed to the age groups above 65 . This is true for all educational levels.

The age decomposition of the differences in life expectancy between 1991 and 2001 allows for a better assessment of the age-specific contribution. The age decomposition is calculated according to Arriaga's formula (1984). The contribution of mortality differences in an age group $x$ to $x+n$ to differences in the life expectancy at age 25 between 1991 and 2001 is calculated for each educational level separately (sea also Preston et al. 2001, pp. 64-65).

The dark line in Fig. 3 represents the decomposition of the increase between 1991 and 2001 for the total population. The increase in life expectancy occurs at all ages, but is concentrated in the age group 55-80 for men and 60-85 for women with a peak towards the older ages among women. Overall this suggests an ongoing rectangularisation of the survival curves. The decomposition by education shows a comparable pattern for all educational levels. At the lowest level, however, the decomposition reveals negative contributions under age 55, as illustrated by the lighter line for primary education. The rectangularisation of the survival curve and 

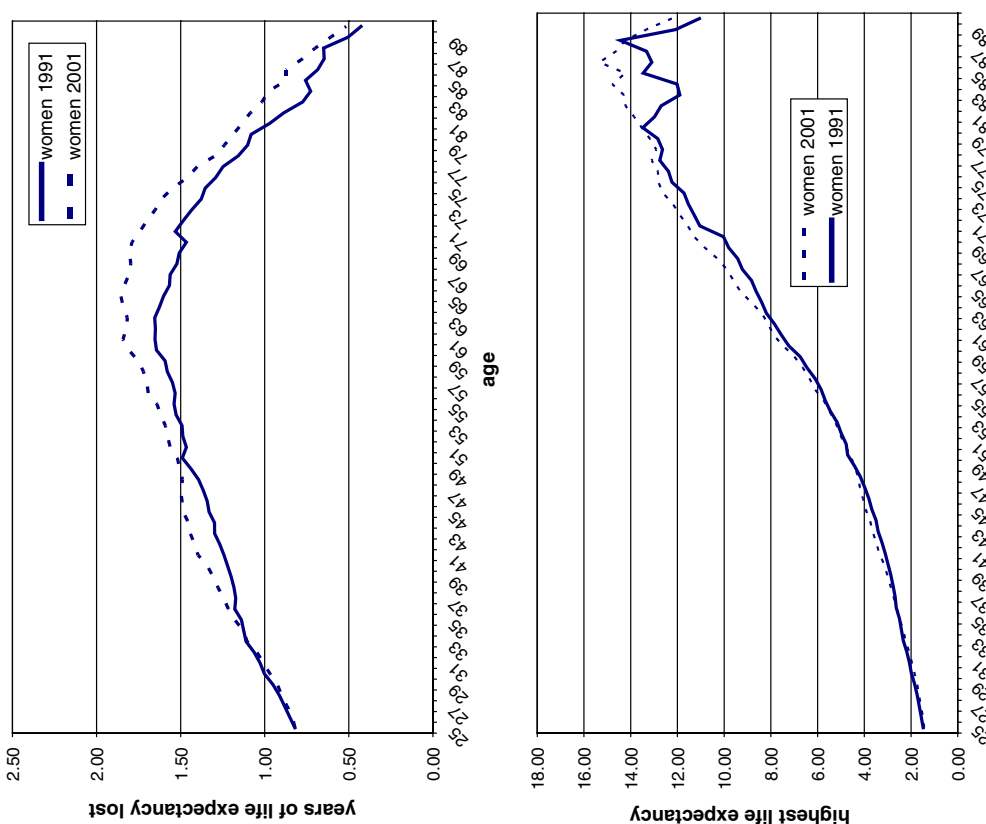

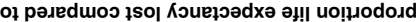
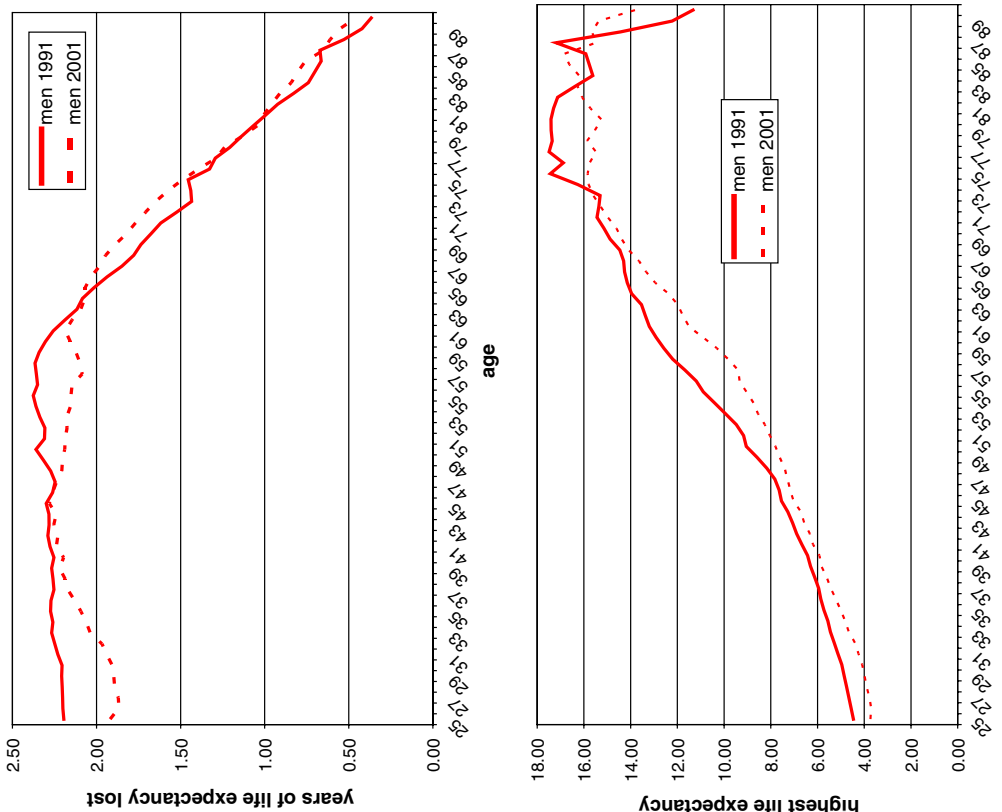

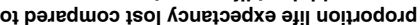

है

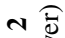

这 
Table 4 Increase in life expectancy by educational level between 1991 and 2001 for men and women at selected ages

\begin{tabular}{lcllll}
\hline & No diploma & Primary & Low secondary & High secondary & Tertiary \\
\hline Men & & & & & \\
25 & 0.11 & 1.45 & 1.66 & 1.94 & 2.35 \\
35 & 0.15 & 1.55 & 1.73 & 1.91 & 2.29 \\
45 & 0.23 & 1.53 & 1.71 & 1.83 & 2.16 \\
55 & 0.56 & 1.73 & 1.79 & 1.80 & 2.10 \\
65 & 0.86 & 1.55 & 1.68 & 1.65 & 1.86 \\
75 & 0.53 & 0.92 & 0.98 & 1.04 & 1.10 \\
85 & 0.10 & 0.34 & 0.45 & 0.27 & 0.50 \\
Women & & & & & \\
25 & -0.49 & 1.09 & 1.35 & 1.42 & 2.21 \\
35 & -0.18 & 1.12 & 1.32 & 1.41 & 2.17 \\
45 & -0.05 & 1.14 & 1.22 & 1.30 & 2.06 \\
55 & 0.25 & 1.32 & 1.19 & 1.29 & 1.97 \\
65 & 0.45 & 1.32 & 1.17 & 1.34 & 1.81 \\
75 & 0.19 & 1.02 & 0.86 & 0.58 & 0.69 \\
85 & -0.08 & 0.62 & 0.52 & & \\
\hline
\end{tabular}

the concentration of mortality around the modus progress more strongly among the tertiary educated than among the primary educated.

\section{Discussion}

\subsection{Data Aspects}

The dataset used is rather exceptional. Only Scandinavian countries have similar datasets on mortality. For Finland, analyses based on comparable data have been published earlier (Valkonen et al. 1990) and recent studies allow comparison of life expectancy by social class across several census records linked to death certificates from 1970 onwards (Martikainen et al. 2001a).

Outside the Scandinavian world, this kind of large comprehensive dataset with census records directly linked to mortality registers is exceptional. The dataset is highly reliable with regard to mortality and is not plagued by a numeratordenominator bias. As the complete population is covered through the population register, the data are not subject to selection bias as in surveys. As a consequence, research results can be considered as very robust, all the more since three years of follow-up were compared for both periods, with each time about 300,000 deaths.

The most important data limitations are without doubt determined by the nonresponse for the educational questions, especially in the census of 1991. Much time was devoted to analysing and cleaning the data and to test the effect of alternative choices in dealing with non-response. To summarise, three important problems can 

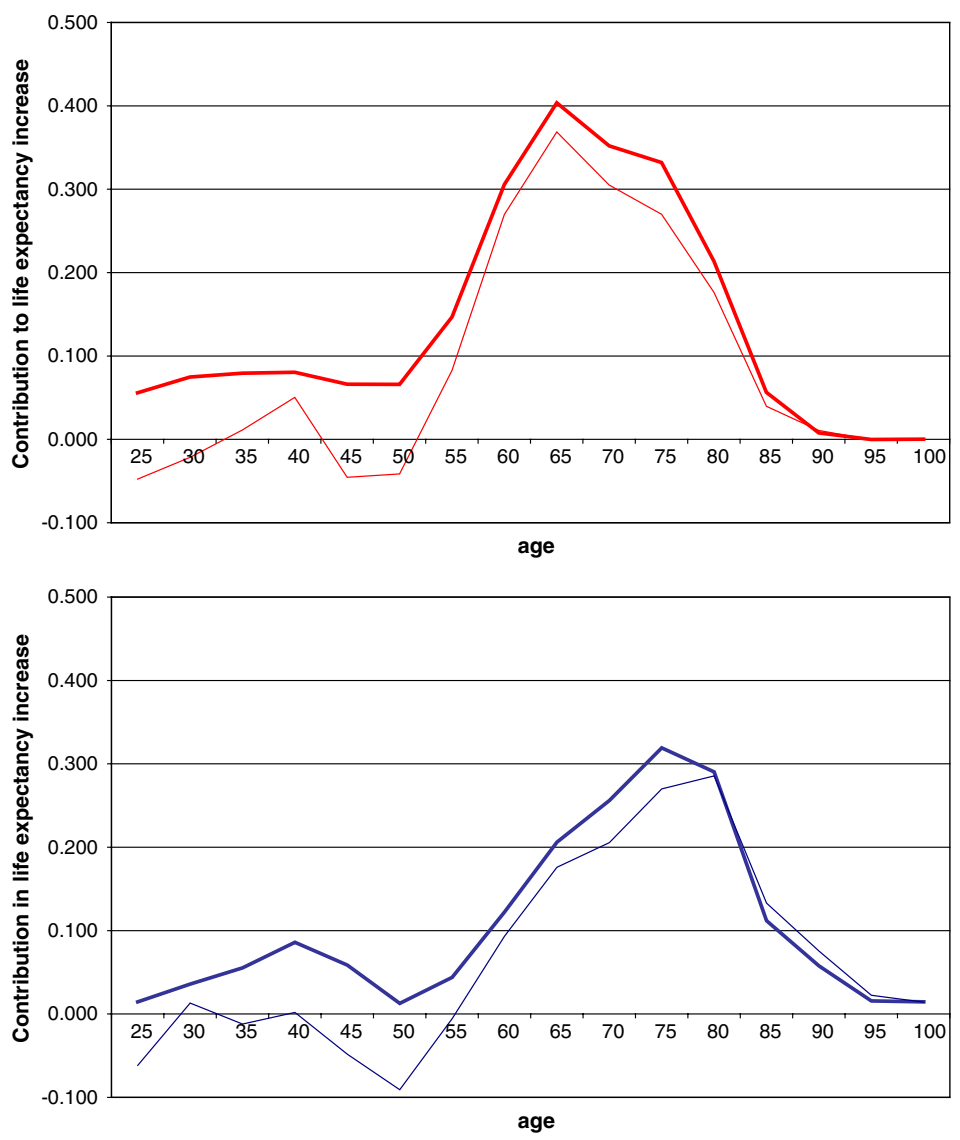

Fig. 3 Decomposition of the age-specific contribution to life expectancy increase between 1991 and 2001 for the total population (dark line) and for primary educated (light line) men (upper) and women (lower)

be pinpointed: educational distribution among the oldest-old and life expectancy and trend in life expectancy among the lowest educated persons.

For the oldest-old, especially above age 90, the number of higher educated is so low and the number of missing answers so high that research results have to be considered with utmost caution. Therefore, we preferred to draw most tables and graphs up to the age of 90 only, even if we closed the life tables at age 100.

As the 1991 census data did not allow to distinguish non-response and persons without formal education, we could not simply eliminate the non-response from the analyses. In addition, merging the lowest educational group with persons with primary education, as is often done in international research, leads to an unjustified lowering of the life expectancy of primary educated and an unnecessary loss of information. As a consequence, we preferred to maintain the distinction and to warn about the potentially poor reliability of results for the group without formal education. 
Our database allows for correction of the missing information in the 1991 census based on the information in the 2001 census. However, this procedure may possibly have introduced more bias, as the corrections could not be applied to those who died during the first observation period.

For the calculations of the life tables we thus used the categories as entered in 1991, maintaining the important group "without formal education or no answer". For 2001, the same classification was respected. Although it was possible to make a distinction between item non-response and persons without formal education, we kept them together in order to maintain comparability with 1991. This approach probably underestimates mortality in the population with no diploma in 1991 because persons who ought to be part of the higher educated groups are collapsed with the lowest educated. Inversely, we also overestimate mortality in the 2001 population because of the larger representation of terminally ill persons among the much smaller non-response group. The combination of both may result in an underestimation of the progress in life expectancy among the lowest educated and an overestimation of the increase in inequality over time. This could indeed be the case, as the difference observed between the educational categories is much larger between the non-diploma group and the primary educated than the differences between other adjacent groups.

As a result, the category "without formal education" has to be treated with caution, even though the results are partially corrected by taking into account a follow-up period of three years. The procedure also influences measures, such as the maximum difference in life expectancy between highest and lowest educated. In order to obtain a good estimation of the disparities in life expectancy, it may be more appropriate to use persons with primary education as reference group. On the other hand, the inclusion of all respondents in the analysis, including non-response, leads to more reliable measures for total life expectancy and ipso facto for summary indices of inequality based on total life expectancy.

Finally, sensitivity analyses were conducted to estimate the impact of different procedures in dealing with non-response. We tested the impact of distributing nonresponse proportionally over all educational levels compared to allocating all missing answers to the lowest educational level. The results for the tertiary, secondary and even primary educated appear to be robust, the gradients and differences in life expectancy between 1991 and 2001 remain stable. This is not the case for the group without formal education. Their relative position remains unchanged, but the change between 1991 and 2001 can be, depending on the procedure, slightly worse or considerably better than the presented results.

\subsection{Evaluation of the Results}

The overall result points to an increase in life expectancy at age 25 in all educational groups, with the exception of women without formal education. This observation is consistent with the general increase in life expectancy observed during the period 1991-2001. Higher educated live longer and have a higher increase in life expectancy at each age until the age of 90 . At the oldest ages, life expectancy tends 
to converge. There are major differences in life expectancy by educational attainment and these differences increase during the observation period. As life expectancy continues to increase, so does the gap between the highest and the lowest educated. As a result, absolute inequalities in life expectancy at age 25 by educational level increased between 1991 and 2001. This finding is consistent with the results observed in Finland. The overall trend is a widening of absolute life expectancy inequalities due to the faster mortality decline in the higher educated groups. Our findings are also consistent with research using other methods and other datasets on mortality disparities in developed countries as reported by Pappas for the US (Pappas et al. 1993) and by Harding for England and Wales (Harding 1995). More recently, Mackenbach et al. (2003) reported a widening in the relative gap in death rates for the period 1981-1985 and 1991-1995 in six European countries, but not in absolute differences. Absolute differences were fairly stable except in Finland where an increase occurred. The choice between relative and absolute measures of inequality is not unimportant as these measures sometimes evolve in a different direction. Kunst and Mackenbach (1995) argue that, as a general rule, a public health policy perspective should consider absolute differences, because these are what really matter for public health.

We have to be cautious in interpreting the observed trend differences across studies and countries as the reasons can be substantial, methodological or related to differences in data collection, construction and classification. Two common threads are clear however: the gap in educational inequality is not closing, but is stable at best or even widening, and the widening is mostly due to the faster decline of mortality among the highest educated groups.

Gender differences in health inequality, with a steeper gradient in men than women, have repeatedly been found (Arber and Lahelma 1993; Koskinen and Martelin 1994; Arber 1997) and confirmed for Belgium (Gadeyne 2006). Interestingly, recent data have shown that the social gap is now widening faster among women than among men, reducing gender differences in this regard. The Belgian data confirm the classic gender difference, but also the faster increase in inequality among women. The social gradient in women is becoming more comparable to that in men. Belgium is one of the high-income countries where the narrowing of sex differentials in life expectancy started relatively recently, in the mid 1990s (Glei and Horiuchi 2007). The question is, whether both trends are interlinked. Table 3 suggests that all educational levels contribute to the decrease in the gender gap through a slower increase in life expectancy in women than in men. Among the lowest educated women, life expectancy even decreases between 1991 and 2001. The picture is comparable to the findings for Norway and Denmark from the early 1980s to the early 1990s, when mortality trends among women developed less favourably and even stagnated among lower educated women (Mackenbach et al. 2003).

In most educational groups, all ages benefit from the increase in life expectancy (Table 4). The contribution of specific age groups to changes in life expectancy between 1991-1994 and 2001-2004 can be decomposed. Figure 3 illustrates that, for men, the ages between 55 and 80, and for women between 60 and 85, contribute substantially to the increase in life expectancy. The decrease in the gender gap is 
mainly situated in the same age range. Analysis of age-specific death rates (not presented) shows that gender differences are increasing among the oldest-old above age 90 . Under the age of 55, differences remain relatively stable for the total population but show diverging patterns by educational level. Among the higher educated, the gender gap tends to narrow, while among the lower educated and especially among the numerically important group of the lower secondary educated, the gender gap continues to increase. Among women, almost all ages contribute to the increase in inequalities in life expectancy. Among men the picture is more mixed. Only among men without formal education is mortality inequality compared to the highest educated increasing over the whole age range. For all other educational levels, inequality is decreasing in the age group 60-80.

The age-specific contribution to a change in life expectancy is necessarily restricted by the existing intensity of the mortality rate. Once mortality is virtually non-existent at a certain age, it becomes impossible to contribute to future increases in life expectancy in this age group. The low mortality rates under the age of 50 explain the small contribution to life expectancy gains at these ages. Mortality among women with the lowest educational level increases between 25 and 65 , resulting in negative increase in life expectancy under the age of 50 years (Table 4).

\subsection{Interpretation of the Results}

The relation between education and health is of course well known and amply documented in the literature. The pathways linking education and mortality have been discussed for a long time. The role of education as a social determinant of health is now largely accepted and concurrent hypotheses (spurious relationship, drift hypothesis or reverse selection, diminished access to health care, etc.) at best only partially contribute to the main causal relationship (Macintyre 1997). A vigorous debate is still going on among researchers concerning the practical mechanisms through which socioeconomic position and education in particular affect health. Intervening mechanisms have been presented as mutually excluding or even antagonistic (Davey-Smith et al. 1998), but appear to be often simply juxtaposed. According to Ross and Wu (1996), the intervening mechanisms linking education and mortality (or health in general) can be classified in three types: economic resources, psychosocial resources and health behaviours. The general impression is that health and education are linked through complex and multifaceted pathways that are difficult to disentangle, even with regard to the respective contribution of education as "knowledge" and education as the indicator of past and future socioeconomic position.

\subsection{Are We Moving Towards More Inequality?}

The question is: why is there a widening in life expectancy by educational level, or even more specifically: why don't lower educated people profit as much from the general increase in life expectancy? 
This discussion is particularly important with regard to the explicit goals of the World Health Organization (WHO 1985; WHO Regional Office for Europe 1998) and the European Union to reduce socioeconomic health inequalities. The second target of the Health for All policy framework of the WHO European Region (Health21) addresses the problem of reducing health inequalities within countries. The target is to reduce by the year 2020 the health gap among socioeconomic groups by at least one fourth in all member states by improving the level of health of disadvantaged groups. Contrary to this political aim, health disparities seem to have increased in absolute terms particularly as measured by mortality, the most radical health indicator (Koskinen 2003).

The interpretation of these findings is complex. As pointed out, the trends in terms of progress and in terms of inequality in life expectancy is unevenly distributed across age groups and sexes. Moreover, for interpretation we also have to take into account the change in the proportions of educational categories within the population. This change in composition has more than one relevant consequence for the assessment of trends in health equality.

As the proportion of the lower educated in the total population has decreased quite dramatically, Mackenbach et al. (2003) noted that lower educational groups may represent a more "extreme" group in terms of (relative) socioeconomic position and associated material, behavioural and psychosocial characteristics.

A related hypothesis is that, as the proportions of the lowest educated are shrinking, inverse health selection effects become increasingly important in explaining poor health status among the lowest educated. Martikainen et al. (2001b) have stated that the dwindling in size of a lower status is an unlikely cause for the increasing life expectancy difference in their Finnish data and argue that the explanation is more likely to be found in differential health behaviour.

Among the lowest educational groups in Belgium between 1991 and 2001, both the tendency towards a more "extreme" group and the inverse selection process are possibly contributing to the trend in the youngest age groups where the lowest educational levels have become extremely small. This can help to explain the slow progress in life expectancy and even the increase in mortality among lower educated women in the younger age groups. It is, however, relatively unimportant in the older age groups where the lowest educated still represent a major group within the population.

There is a more profound process taking place. A policy intended to reduce inequity in health has to address the social conditions contributing to unequal chances in health. The second target of Health21 on Equity in health explicitly states "Educational levels produce a similar gradient of health risk to that produced by social class. Since levels of educational attainment are strongly related to levels of deprivation, a key strategy must be to remove the financial, cultural and other barriers that hinder equal access to education" (WHO Regional Office for Europe 1998) and a country as Sweden vowed to tackle health inequalities by creating "social conditions that will ensure good health for the entire population" (Hongstedt et al. 2004). Marmot summarises the problem in a lapidary manner: "If the major determinants of health are social, so must be the remedies" (Marmot 2005) and Koskinen concludes in a comment on widening socioeconomic 
inequalities in Western Europe that in addition "to tackle the factors which have been established as causes of growing inequalities in mortality (...) it is necessary to reduce social inequalities in the general material and cultural resources of health and wellbeing" (Koskinen 2003). In terms of reducing inequality in health this strategy implies changing the composition of the population to guarantee that more people have better chances for an optimal development of health and well-being. In order to assess the implementation of this policy, it is not sufficient to look at the inequalities in life expectancy between educational levels; the distribution of the population over educational levels has to be taken into account too. Measures of social impact such as PALL and CII have to be included in a comprehensive assessment of trends in health inequalities. If not, the overall evaluation tends to conclude to an increase in inequality, while one of the most efficient policies to tackle inequality by changing the upstream conditions is neglected.

Of extreme importance in this regard is the observation that the enormous expansion of the highest educated did not slow down the progress in life expectancy among the highest educated. Quite the contrary, the strongest progress in life expectancy is precisely observed for this rapidly expanding educational group.

In other words, there is no dilution of the educational advantage in this group. A tempting conclusion could be that there is an autonomous effect of education on health. Opening up higher education to a larger group of people distributes more resources over a larger fraction of the population. More people have an additional asset in life to cope with problems they encounter, improve their chances in life (access to occupation, income and wealth) and minimise risks (health behaviour, life style, place of residence, work environment). Some authors have emphasised the role of the ability to cope with life circumstances as a possible pathway for better health prospects of persons with higher SES (Kristenson 2006). Similar concepts proposed in the literature are the "sense of coherence", "the locus of control" or "control beliefs". Several studies have proved the major influence of these abilities or strategies on health outcomes (Bosma 2006). It has also been largely documented that education plays a crucial role in acquiring or improving this ability (Mirowsky and Ross 2007). This has important policy implications: investment in higher education is also investment in population health.

\subsection{Education as Driver of Progress}

This point brings us to a final conclusion concerning the link between compression of mortality and education. The concept of compression is closely linked to that of rectangularisation of the survival curve. More homogeneous populations tend to have a more concentrated distribution of mortality. This is an interesting observation as progress in life expectancy and the secular trend of decreasing mortality have been accompanied in all countries by a compression of mortality.

It is no hazard that life expectancy and concentration have so powerfully progressed together since the Second World War. It is in this context that it appropriate to evaluate the disparities in educational life expectancy in Belgium with reference to life expectancy and mortality distributions of other populations. 
The higher educated can be considered as a vanguard population. "Best-practice life expectancy" (Vaupel) shows the capability of humans, in a given medical and societal context, to extend their length of life.

\section{Conclusions}

Is inequality in health increasing in Belgium or how can we summarise the changes over the last decade of the 20th century?

Several conclusions can be drawn. A major problem is the growing inequality in health. This is in line with most of the literature. The gap between higher educated and lower educated is still growing. This is not only a problem of the very poor. Inequality is present across the entire educational gradient and the increase in inequality is observed among almost all educational groups.

The growing gap in health by educational attainment coincides, however, with increasing life expectancy for all educational levels. This is an important observation because it implies that the growing gap is probably due, for a large part, to the positive effects linked to higher education (directly or as a proxy for underlying dimensions of well-being). This progress is shared by a growing proportion of the population. The democratisation of the educational system and the broad range of measures to guarantee general access to an efficient healthcare system are producing positive results. No doubt, they are important contributors to the steady improvement in health.

The increase in life expectancy among the higher educated is occurring in conjunction with a dramatic increase in the proportion of higher educated in the population. In other words, there is no dilution of the health advantage of the higher educated. Quite the contrary is happening. This is a strong argument against the hypothesis of an enduring inequality in distribution of health by social status. This hypothesis looks at educational attainment as a measurement of relative positions and disregards the aspect of increasing cognitive abilities and greater self-control.

At the same time, it is becoming increasingly important to focus on the health situation of the lower educated. Health selection mechanisms may be partly contributing to the poor health of the small group of persons without formal education, but mechanisms of social marginalisation with a negative health impact cannot be excluded.

The increasing gap between the best performing and all other educational levels shows that there is still plenty of scope to further improve population health. Policyoriented research has to monitor both inequality between groups and composition effects, especially when change in the distribution is part of the pursuit of equity. There is no reason to accept the leverage of education in health outcome in developing countries and deny the importance of the "upstream" conditions in developed countries, especially when we observe that the gradient suggests a general effect of education and not only a problem of deprivation or poverty.

Education is one of the most fundamental collective investments in human capital and the driver of social and economic progress; as such education yields a 
high return on investment. Health improvement can be considered as an unintended result of the progress in education and thus an important extra bonus.

Acknowledgements The data have been collected by Statistics Belgium. This study is funded by Belgian Science Policy, research programme Society and Future. Language editing by Tadek Krzywania (Institute Public Health Belgium).

\section{References}

Abraído-Lanza, A. F., Dohrenwend, B. P., Ng-Mak, D. S., \& Turner, J. B. (1999). The Latino mortality paradox: A test of the "Salmon Bias" and healthy migrant hypotheses. American Journal of Public Health, 89 (10), 1543-1548.

Arber, S. (1997). Comparing inequalities in women's and men's health: Britain in the 1990s. Social Science \& Medicine, 32, 425-436.

Arber, S., \& Lahelma, E. (1993). Inequalities in women's and men's ill health: Britain and Finland compared. Social Science and Medicine, 37(8), 1055-1068.

Arriaga, E. (1984). Measuring and explaining the change in life expectancies. Demography, 21(1), 83-96.

Bosma, H. (2006). Socio-economic differences in health: Are control beliefs fundamental mediators? In J. Siegrist \& M. Marmot (Eds.), Social inequalities in health, new evidence and policy implications (pp. 153-166). Oxford: Oxford University Press.

Bossuyt, N., Gadeyne, S., Deboosere, P., \& Van Oyen, H. (2004). Socio-economic inequalities in health expectancy in Belgium. Public Health, 118, 3-10.

Davey-Smith, G., Hart, C., Hole, D., McKinnon, P., Gillis, C., Watt, G., Blane, D., \& Hawthorne, V. (1998). Education and occupational class: which is the more important indicator of mortality risk? Journal of Epidemiology and Community Health, 52(3), 153-160.

Elo, I. T., \& Preston, S. H. (1996). Educational differences in mortality: United States, 1979-85. Social Science and Medicine, 42(1), 47-57.

Fox, A. J. (Ed.). (1989). Health inequalities in European Countries. Proceedings of European Science Foundation workshops, London, 1984-1986. Aldershot: Gower Press.

Gadeyne, S. (2006). The ultimate inequality. Socio-economic differences in all-cause and cause-specific mortality in Belgium in the first half of the 1990s. NIDI/CBGS-publications, 39. Dordrecht: Kluwer Academic Publishers.

Gadeyne, S., \& Deboosere, P. (2002). Socio-economische ongelijkheid in sterfte op middelbare leeftijd in België. Een analyse van de Nationale Databank Mortaliteit. Brussels: Statistics Belgium.

Galobardes, B., Shaw, M., Lawlor, D. A., Lynch, J. W., \& Davey Smith, G. (2004). Indicators of socioeconomic position (part 1). Journal of Epidemiology and Community Health, 60, 7-12.

Glei, D. A., \& Horiuchi, S. (2007). The narrowing sex differential in life expectancy in high-income populations: Effects of differences in age pattern of mortality. Population Studies, 61(2), 141-159.

Harding, S. (1995). Social class differences in mortality of men: recent evidence from the OPCS Longitudinal Study. Population Trends, 80, 31-37.

Hayward, M., Crimmins, E., \& Zhang, Z. (2006). Consequences of educational change for the burden of chronic health problems in the population. In A. H. Gauthier, C. Y. C. Chu, \& S. Tuljapurkar (Eds.), Allocating public and private resources across generations. Riding the age waves-Vol 2 (pp. 227242). Dordrecht, Netherlands: Springer.

Hongstedt, H., Lundgren, B., Moberg, H., Pettersson, B., \& Agren, G. (2004). The Swedish public health policy and the National Institute of Public Health. Scandinavian Journal of Public Health, 32(suppl 64), 1-64.

Hummer, A. H., Rogers, R. G., \& Eberstein I. W. (1998). Sociodemographic differentials in adult mortality: A review of analytic approaches. Population and Development Review, 24(3), 553-578.

Koskinen, S. (2003). Commentary: Is there a common background behind growing inequalities in mortality in Western European countries? International Journal of Epidemiology, 32, 838-839.

Koskinen, S., \& Martelin, T. (1994). Why are socio-economic mortality differences smaller among women than among men? Social Science and Medicine, 38(10), 1385-1396.

Kristenson, M. (2006). Socio-economic position and health: the role of coping. In J. Siegrist \& M. Marmot (Eds.), Social inequalities in health, new evidence and policy implications (pp. 127151). Oxford: Oxford University Press. 
Kunst, A. E. (1997). Cross-national comparisons of socio-economic differences in mortality. Department of Public Health. Rotterdam: Erasmus Universiteit Rotterdam.

Kunst, A., \& Mackenbach, J. P. (1994a). International variation in the size of mortality differences associated with occupational status. International Journal of Epidemiology, 23(4), 742-750.

Kunst, A., \& Mackenbach, J. P. (1994b). Measuring socio-economic inequalities in mortality. In G. Masuy-Strroobant, C. Courbin, \& P. Buekens (Eds.), Santé et mortalité des enfants en Europe: inégalités sociales d'hier et d'aujourd'hui (pp. 97-127). Louvain-la-Neuve, Belgium-Paris, France: Academia-Bruylant, L'Harmattan.

Kunst, A., \& J. P. Mackenbach (1995). Measuring socioeconomic inequalities in health. Copenhagen: World Health Organization Regional Office for Europe.

Lagasse, R., Humblet, P. C., Hooft, P., Van de Voorde, H., \& Wollast, E. (1992). Atlas of avoidable mortality in Belgium 1980-1984. Archives Public Health, 50, 1-97.

Lagasse, R., Humblet, P. C., Lenaerts, A., Godin, I., \& Moens, G. F. G. (1990). Health and social inequities in Belgium. Social Science and Medicine, 31(3), 237-248.

Lagasse, R., \& Namurois, A. (1982). Variations sociales de divers indicateurs de santé périnatale observées dans trois arrondissements wallons. Population et famille, 56(2), 71-102.

Macintyre, S. (1997). The Black report and beyond: what are the issues? Social Science and Medicine, 44(6), 723-745.

Mackenbach, J. P. (2005). Health inequalities: Europe in profile. Rotterdam: Erasmus MC Rotterdam.

Mackenbach, J., \& Kunst, A. (1997). Measuring the magnitude of socio-economic inequalities in health: An overview of available measures illustrated with two examples from Europe. Social Science and Medicine, 44(6), 751-771.

Mackenbach, J. P., Bos, V., Andersen, O., Cardano, M., Costa, G., Harding, S., Reid, A., Hemström, O., Valkonen, T., \& Kunst, A. E. (2003). Widening socioeconomic inequalities in mortality in six Western European countries. International Journal of Epidemiology, 32, 830-837.

Marmot, M. (1995). Socio-economic differentials in mortality: The Whitehall Studies. In A. Lopez, G. Caselli, \& T. Valkonen (Eds.), Adult mortality in developed countries: From description to explanation (pp. 223-242), Oxford: Clarendon Press.

Marmot, M. (2005). Social determinants of health inequalities. The Lancet, 365, 1099-1104.

Martikainen, P., Mäkelä, P., Koskinen, S., \& Valkonen, T. (2001a). Income differences in morality: A register-based follow-up of three million men and women. International Journal of Epidemiology, 30(6), 1397-1405.

Martikainen, P., Valkonen, T., \& Martelin, T. (2001b). Change in male and female life expectancy by social class: decomposition by age and cause of death in Finland 1971-95. Journal of Epidemiology and Community Health, 55, 494-499.

Masuy-Stroobant, G. (1992). Inégalités sociales et mortalité infantile: un problème d'accessibilité aux services de santé. Reflets et perspectives de la vie économique 31(2,3), 213-225.

Mirowsky, J., \& Ross, E. C. (2007). Life course trajectories of perceived control and their relationship to education. American Journal of Sociology, 112(5), 1339-1382.

Newell, C. (1988). Methods and models in demography. London: Belhaven Press.

Pappas, G., Queen, S., Hadden, W., \& Fisher, G. (1993). The increasing disparity in mortality between socioeconomic groups in the United States. The New England Medicine Journal, 329(2), 103-109.

Preston, S. H., Heuveline, P., \& Guillot, M. (2001). Demography: Measuring and modeling population processes. Oxford: Blackwell Publishers.

Raes, V., Kerkhofs, E., \& Louckx, F. (Eds.). (1993). Sociale ongelijkheid en verschillen in gezondheid. Brussel: VUBPRESS.

Razum, O., \& Rohrmann, S. (2002). The healthy migrant mortality effect: role of selection and late entry bias. Artherosclerosis, 64(2), 82-88.

Razum, O., Zeeb, H., \& Rohrmann, S. (2000). The 'healthy migrant effect' - not merely a fallacy of inaccurate denominator figures. Internation Journal of Epidemiology, 29, 191-192.

Ross, E. R., \& Wu, C.-L. (1996). Education, age and health. Journal of Health and Social Behaviour, 37, 104-120.

Schepers, R., Smet, M., \& Van Wanseele, C. (1985). Sociale ongelijkheid in ziekte, dood en gezondheidszorg. Welzijnsgids, 23, 1-21.

Shkolnikov, V., Valkonen, T., Begun, A., \& Andreev, E. M. (2001). Measuring inter-group inequalities in length of life. Genus, LVII(3-4), 33-62.

Shryock, H. S., Siegel, J. S., et al. (1971). The methods and materials of demography. Washington D.C: U.S. Government Printing Office. 
Valkonen, T. (1993). Problems in the measurement and international comparisons of socio-economic differences in mortality. Social Science and Medicine, 36(4), 409-418.

Valkonen, T. (1999). The widening differentials in adult mortality by socioeconomic status and their causes. In J. Chamie \& R. L. Cliquet (Eds.), Health and mortality. Issues of global concern. Proceedings of the symposium on health and mortality (pp. 291-312) November 1997, Brussels: United Nations, Population Division, Department of Economic and Social Affairs, United Nations Secretariat and Family Study Centre, Flemish Scientific Institute.

Valkonen, T., Martelin, T., \& Rimpela, A. (1990). Socio-economic mortality differences in Finland 197185. Helsinki, Central Statistical Office of Finland, Studies nr. 176.

Van Oyen, H., Bossuyt, N., Deboosere, P., Gadeyne, S., Abatih, E., \& Demarest, S. (2005). Differential inequity in health expectancy by region in Belgium. Soc.-Präventivmed, 50, 301-310.

Van Oyen, H., Bossuyt, N., Deboosere, P., Gadeyne, S., \& Tafforeau, J. (2002). Differences in health expectancy indicators in Belgium by region. Archives of Public Health, 60(6), 341-362.

Vuylsteek, K. (1984). Sociale ongelijkheid tegenover ziekte en dood. Tijdschrift voor geneeskunde, 40(5), 291-299.

WHO (1985). Formulating strategies for health for all by the year 2000: Guiding principles and essential issues. Geneva: World Health Organization.

WHO Regional Office for Europe (1998). Health21, An introduction to the health for all policy framework for the WHO European Region. European Health for All Series (5), 36. 